\title{
Bilingual Education Helps to Improve the Intelligence of Children
}

\author{
Mai Thanh Nguyen ${ }^{1, *}$ \\ ${ }^{1}$ Vietnamese American School System, 242 Cong Hoa, Hochiminh City, Vietnam \\ *Correspondence: 242 Cong Hoa, Hochiminh City, Vietnam. E-mail: thanhmai@vass.edu.vn
}

Received: December 1, 2017

Accepted: December 14, 2017 Online Published: December 20, 2017

doi:10.5430/wjel.v7n4p11

URL: https://doi.org/10.5430/wjel.v7n4p11

\begin{abstract}
This study uses an IQ test to test the "intelligence" of two pupil groups: one is studying the bilingual program and the other is learning the monolingual program plus English subject as a foreign language. The study discovers that both groups have increased the IQ score after seven months at schools. This result proves that IQ scores are not fixed but can increase through ages of children from 6 to 11 as well as through education. However, the group of bilingual pupils has higher increase of IQ scores in comparison with the monolingual group, proving the bilingual education can help to better improve the intelligence of children. This is agreeable with the results of many previous researches.
\end{abstract}

Keywords: bilingual education; intelligence; IQ test

\section{The Benefits of Bilingual Education}

In recent years there have been many studies around the world on the benefits of bilingualism and bilingual education. The benefits of bilingual programs have been documented and supported in numerous studies. Cummins (2003) suggests that bilingual programs have a positive effect on language development and child education, supporting children in developing greater flexibility in their thinking through habits and processing information through two different languages. Skutnabb-Kangas (2000) explains that the bilingual program improves business opportunities, leads the society, and maintains superiority. Real evidence seems to fully support the broad advantages of the bilingual and multilingual education program, recognized by several studies which state that these programs are essential for the development of resources. That force is language, culture and intellect.

Baker (2006) points to eight main advantages of bilingual education (excluding social, ethnic or community aspects):

1) the level of proficiency in both languages allows communication to be more effective and broader;

2) multicultural understanding

3) knowing two languages increases a person's chances for literature, giving them a deeper understanding of history, traditions and perspectives.

4) increase achievement in the classroom

5) develop better awareness

6) increased self-esteem, especially for ethnic minority children

7) increased self-confidence at local, regional and national levels

8) economic advantage due to increased employment opportunities

Specifically on the topic of cognitive development, Baker (2006) deals with information processing skills and education levels that can be developed in two languages, as well as through four skills: listening - speaking - reading - writing, helping the entire cognitive system to develop to some extent where one or both languages are not fully implemented, cognitive function and academic achievement may be badly affected. Many researchers (Hamers \& Blanc, 1983; Cumming, 2012) see many other benefits of bilingualism, such as superior skills in the first language, higher IQ and, again, increased flexibility and cognitive development.

New research in bilingual neuroscience has found that bilingual proficiency, especially from childhood, not only 
enhances people's ability to concentrate, but can also protect against the initiation of dementia and cognitive decline. These discoveries lead to:

- Understand how the brain organizes speech and communication tasks.

- Learn more about how specific brain activity can prevent or slow down dementia and other age-related cognitive problems.

- More targeted and effective therapy to help bilingual individuals restore brain injury communication skills.

New studies have found that bilingual children attain language milestones at the same age as monolingual children. They also did not show any evidence of language disorder. Indeed, infants have the ability to use rhythmic signals to distinguish two languages from the first days of life.

In fact, bilingualism can give children an advantage at school. Bilingual children are found to be better able than their monolingual classmates to focus on a task thanks to the ability to adjust distraction. Concentration - a marker of good working memory - is similarly found in bilingual adults, especially those who are bilingual at an early age. It is possible that bilingual management helps the brain form and maintains concentration while ignoring irrelevant information.

Other studies suggest that bilingualism can delay the onset of age-related dementia, including Alzheimer's, for up to four or five years. Although scientists do not know why bilinguals are capable of producing such cognitive storage, some theories suggest that bilingualism can increase the amount of blood and oxygen flowing into the brain and keep the nerve connections healthy to help prevent memory-related illness (Bialystok, 2011).

Most recently, scientists have discovered that bilingual adults have a darker gray matter (brain tissue associated with neurons and neural fibers that process information) in the left hemisphere, where controls communication and language skills (Olulade et al, 2016). This difference is particularly evident in bilingual learners before the age of five and second language proficient. This finding proves that early bilingualism will reshape the structure of the brain (Mechelli et al, 2004). Especially, when bilinguals switch between their two languages in communication or literacy, they activate the activity in the hemisphere significantly relative to those who speak a particular language, especially in the area. The frontal area, called the prefrontal adrenal area, serves the executive control on bilingual mode. This extensive neurological activity is striking and predictable on brain patterns that serve as a "neurological sign" for bilingualism (Bialystok, 2001).

In addition, neuroscience research is promising to evaluate and treat bilingual patients who are unable to speak or understand speech after a brain injury. Research shows that the ability to use language rehabilitation, not just one, but both languages in bilinguals after injury are much higher than those who use a language.

Contrary to the widely accepted scientific opinion of decades ago, recent researchers have discovered the neuroplasticity nature of our brains (Cassidy et al. 2011; Roche et al. 2013). This means that our intellectual or creative potentials of human being are not set in genetic stone, but can be improved in certain ways. Just like a body's muscles, the strength and even the size of the brain can be developed. There have been growing evidences that musical training was associated with higher IQ scores and cognitive abilities (Schellenberg \& Peretz, 2008; Forgeard et al., 2008; Hille et al., 2011). Schlaug (2015) showed that the brains of musicians have more gray matter than those who don't play an instrument. Many researches have also proved that there is a strong correlation between relational skills and IQ scores, and ones can increase IQ scores by improving their relational skills (Cassidy et al. 2011; Roche et al. 2013). Learning a new language is also proved to increase the size of the brain. A study conducted by the Swedish Armed Forced Interpreter's Academy has shown that the size of the hippocampus, the part related to language of the brain, increased significantly after thirteen months of intense language learning (Martensson et al.,2012).

As mentioned above, many researchers believed that bilingualism and bilingual education can help to increase IQ. However, there has not been any evidence in the relation of these two. Therefore, this paper will present a direct evidence of bilingual education helps to increase IQ.

\section{Implementing a Bilingual Program at the Vietnamese American School System in Vietnam}

Vietnamese American School System (VASS) was established 2005. Located in Ho Chi Minh City, it is a private school offering a bilingual program from grade 1 to grade 12. Most of the pupils at VASS are Vietnamese who want to take higher education in English speaking countries, such as the USA, the UK, Australia, Canada, New Zealand, etc. or study at International universities in Vietnam or Asian countries. Besides a minority of pupils whose parents are English natives or who were born in English speaking countries, the majority does not speak English at home. At 
VASS, in the mornings from Monday to Friday, all pupils learn the Vietnamese program regulated by the Ministry Of Education and Training, (MOET). In the afternoon, they study the English program designed by the School's Department of International Programs and Curriculum (DIPAC). The English programs are based on the Cambridge International Examinations' programs and qualifications (CIE, 2016). With the motto "brighten your future", VASS has standardized its international programs with the outcomes of primary (after Grade 5), junior secondary (after Grade 9) and senior secondary (after Grade 12) are Cambridge Primary, IGCSE (International General Certificate of Secondary Education) and Cambridge A Level, respectively.

As mentioned above, in order to be regarded as a bilingual or immersion program, "at least 50 percent of the academic year must be provided in the second language for the program" (Genesee, 1987). In the case of VASS, half of the program (morning lessons) is taught in Vietnamese and the other half (afternoon lessons) is conducted in English (as the second language).

Primary pupils study 4 periods in mornings and 4 periods in afternoons ( 45 minutes per period). Therefore, in total every week, Primary pupils will study 20 periods in Vietnamese and 20 periods in English. A timetable of a grade is exampled In Table 1.

Table 1. Example Timetable of a Class at VASS

\begin{tabular}{llllll}
\hline \multicolumn{7}{l}{ MORNING SESSIONS - VIETNAMESE CURRICULUM } & & \\
\hline Period & MONDAY & TUESDAY & WEDNESDAY & THURSDAY & FRIDAY \\
\hline 1 & Assembly & Fine Arts & Science \& Society & P.E. & Music \\
2 & Phonics & Phonics & Phonics & Phonics & Phonics \\
\hline BREAK & & & & \\
\hline 3 & Moral & Maths & Maths & Maths & Maths \\
4 & Script Practice & Script Practice & Craft & Script Practice & Life Skills \\
\hline LUNCH & TAKING NAP & & & \\
AFTERNOON SESSIONS & ENGLISH CURRICULUM & & \\
\hline Period & MONDAY & TUESDAY & WEDNESDAY & THURSDAY & FRIDAY \\
1 & Reading \& Voc. & English & Science & ICT & Maths \\
2 & Phonics & English & Science & ICT & Maths \\
\hline BREAK & & & & Music \\
\hline 3 & English & Science & Grammar \& Voc. & Maths & Phonics \\
4 & English & Science & English & Maths &
\end{tabular}

Secondary pupils have similar timetables. However, there are seven subjects at junior grades and five subjects at senior grades in the English program are taught as shown in Table 2.

Table 2. Subjects and Periods of English Program for Junior and Senior Secondary Levels

\begin{tabular}{lclc}
\hline Junior Secondary Level (Grade 6 to 9) & \multicolumn{2}{l}{ Senior Secondary Level (Grade 10 to 12) } \\
\hline Subject & Number of period /week & Subject & Number of period /week \\
\hline Academic English & 5 & Academic English & 6 \\
Maths & 4 & Maths & 4 \\
Science & 4 & Science & 4 \\
Geography & 2 & Economics & 4 \\
ICT & 2 & ICT & 2 \\
French Language & 2 & & \\
Music & 1 & & \\
\hline
\end{tabular}


Whereas, there are two English programs offered at most of the public primary schools in Ho Chi Minh, including (i) Intensive English Program (IEP), in which pupils will study 8 periods of English per week; and (ii) Elective English Program (EEP), in which pupils study 4 periods of English every week.

\section{IQ Test and Results}

In this study, an IQ Test has been used to evaluate the "intelligence" of pupils before and after seven months of taking bilingual study in comparison with those who just study English as a foreign language. At the beginning of the school year in September 2016, all primary pupils at VASS from Grade 2 to Grade 5, that represent for group of bilingual learners, took the IQ Test. In comparison, all pupils from Grade 2 to Grade 5 at Nguyen Van Troi Public Primary School (called NVT) also took the same IQ Test in September 2016. The number of pupils of each Grade at both schools taking the IQ Test is given in Table 3.

Table 3. The Number of Pupils of Each Grade at VASS and NVT Taking the IQ Test

\begin{tabular}{cccc}
\hline & VASS & & NVT \\
\hline Grade 2 & 36 & Grade 2 & 19 \\
Grade 3 & 18 & Grade 3 & 59 \\
Grade 4 & 20 & Grade 4 & 63 \\
Grade 5 & 24 & Grade 5 & 137 \\
Total & 98 & Total & 278 \\
\hline
\end{tabular}

Figure 1 and 2 show the histogram of the IQ Test at both schools in September 2016. The distributions of the score ranges of both schools are close to the normal distribution, approving that the IQ Test and the results have high confidence. As shown in the figures, the average scores of both schools are very close, with 99.4286 and 99.7014 for VASS and NVT respectively.

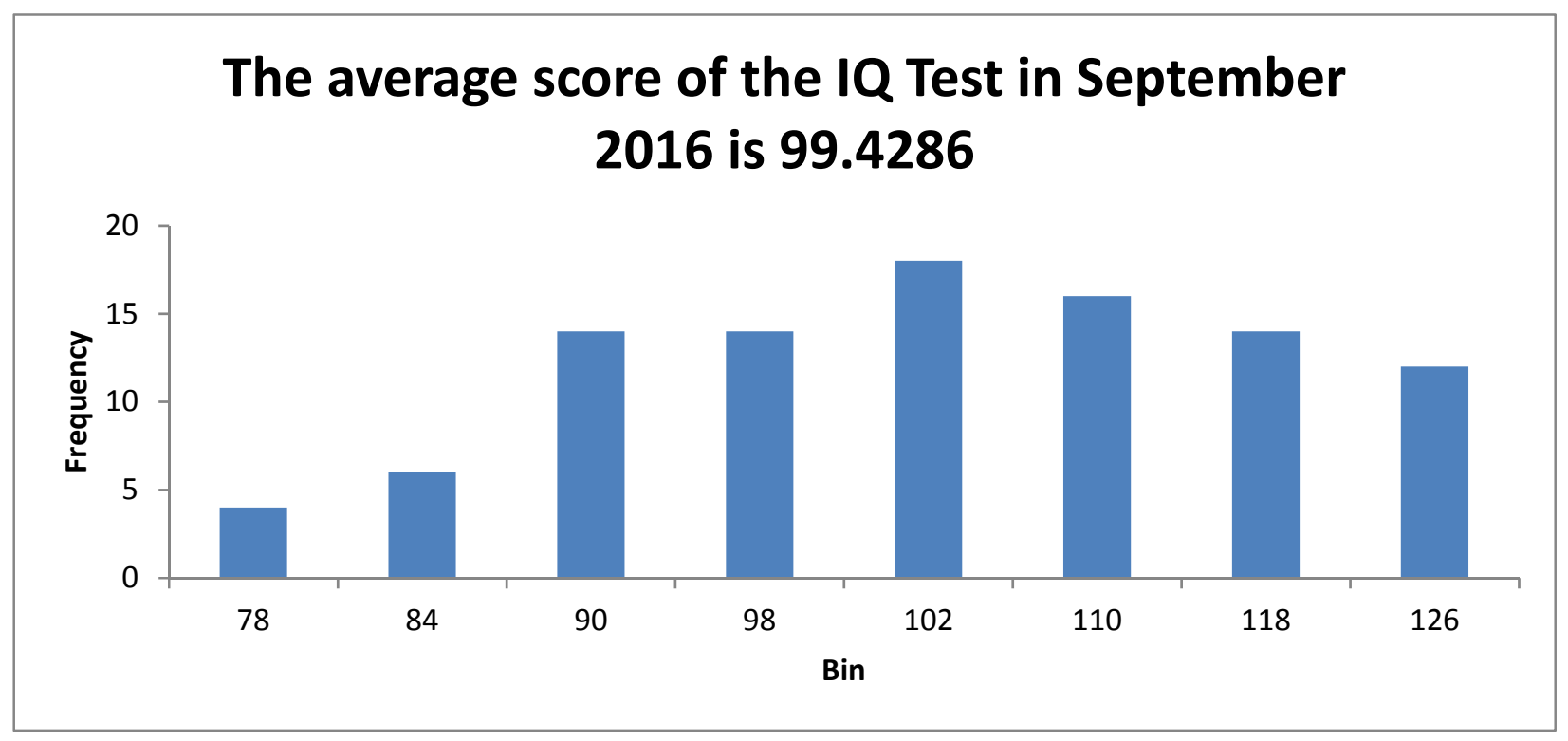

Figure 1. The Histogram of the IQ Test at VASS in September 2016 


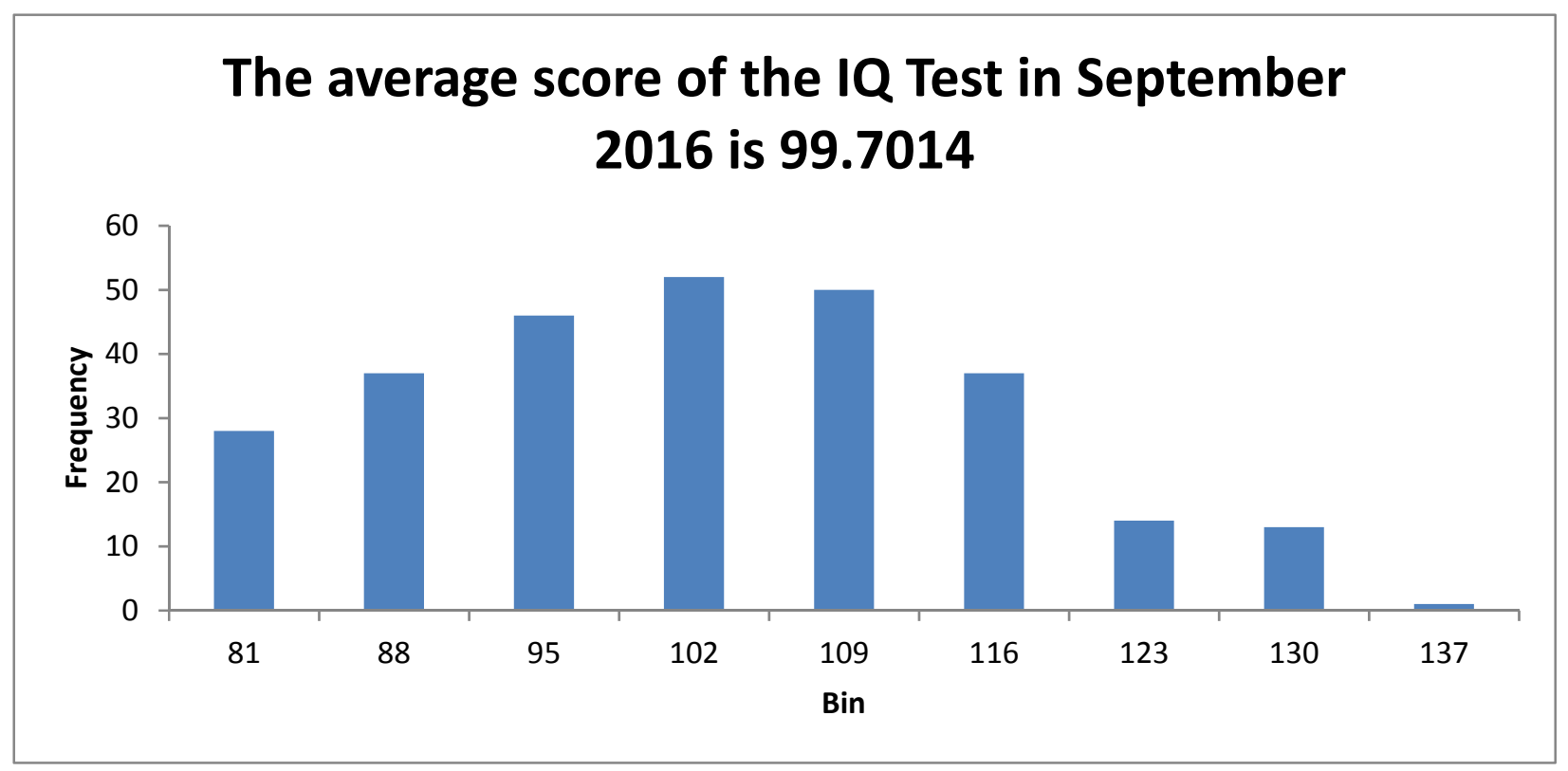

Figure 2. The Histogram of the IQ Test at NVT in September 2016

Then, by the end of the school year in April 2017, the IQ Test was given for those pupils again. Table 4 shows the average scores of both schools for the test in September 2016 and April 2017.

Table 4. Average Scores of the IQ Test of VASS and NVT in September 2016 and April 2017

\begin{tabular}{cccc}
\hline School & Score in Sep. 2016 & Score in April 2017 & Increase \\
\hline VASS & 99.4286 & 100.6122 & 1.1836 \\
NVT & 99.7014 & 100.2266 & 0.5252 \\
\hline
\end{tabular}

Interestingly, as shown in Table 4, the average score of VASS increases 1.1836 points in the period of seven months whereas that of NVT increases only 0.5252 . The results can bring to some conclusions:

- IQ scores are changed when people grow up and are educated. In this study, the increase of IQ score is obviously evident at least during the ages of primary children, that is from 6 to 11 years old.

- The difference of IQ score increases of two schools in this study can be the strong evidence of the benefit of bilingual education. In other words, a bilingual program obviously helps children improve their intelligence. This is agreeable with the results of previous studies (Hamers \& Blanc, 1983; Cumming, 2012; Cassidy et al. 2011; Johan et al, 2012; Roche et al. 2013).

Figure 3 and 4 show the histogram of the IQ Test at VASS and NVT in April 2017. Once again, these figures confirm the consistency and reliability of the IQ Test at both schools. 


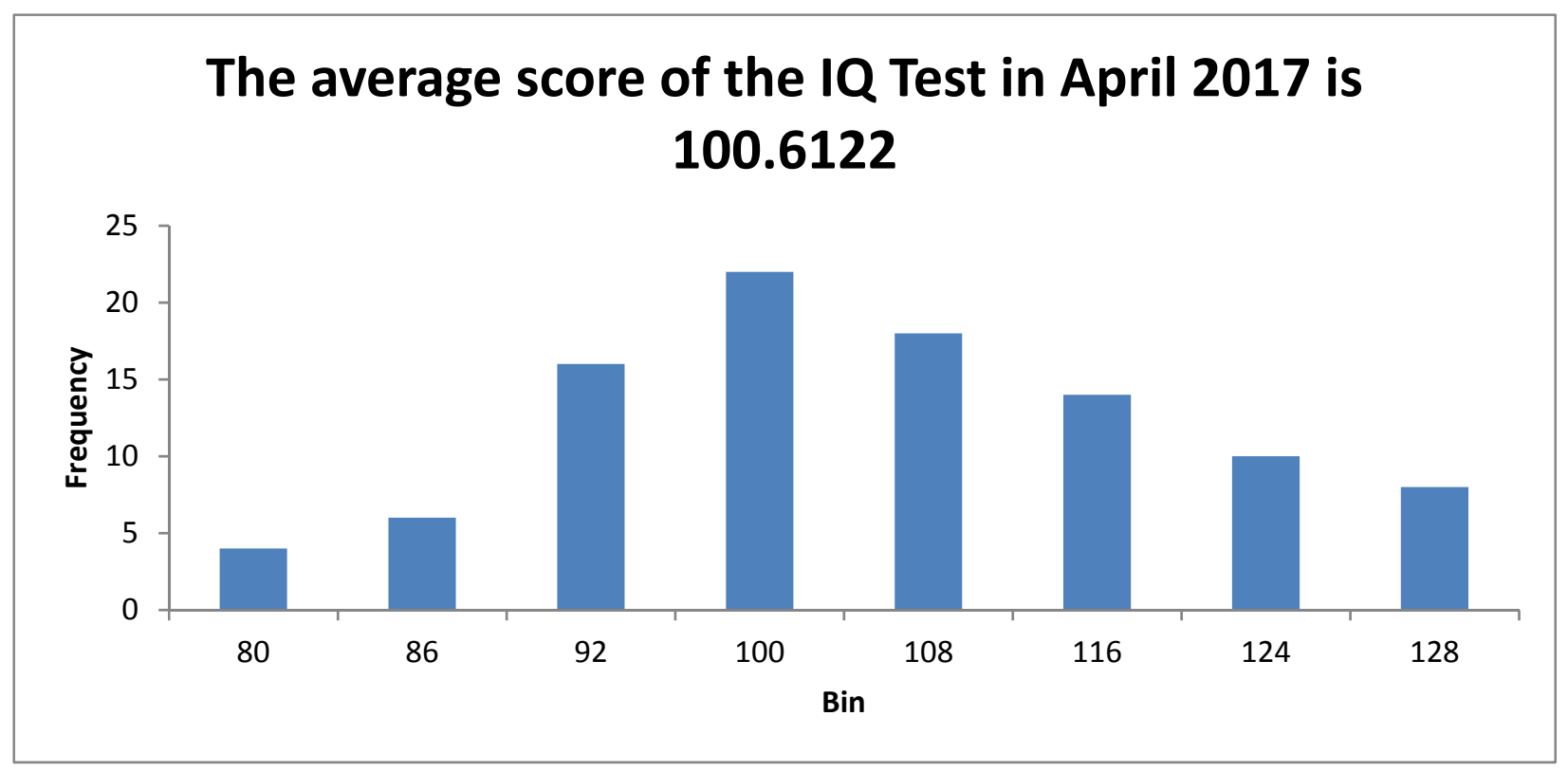

Figure 3. The Histogram of the IQ Test at VASS in April 2017

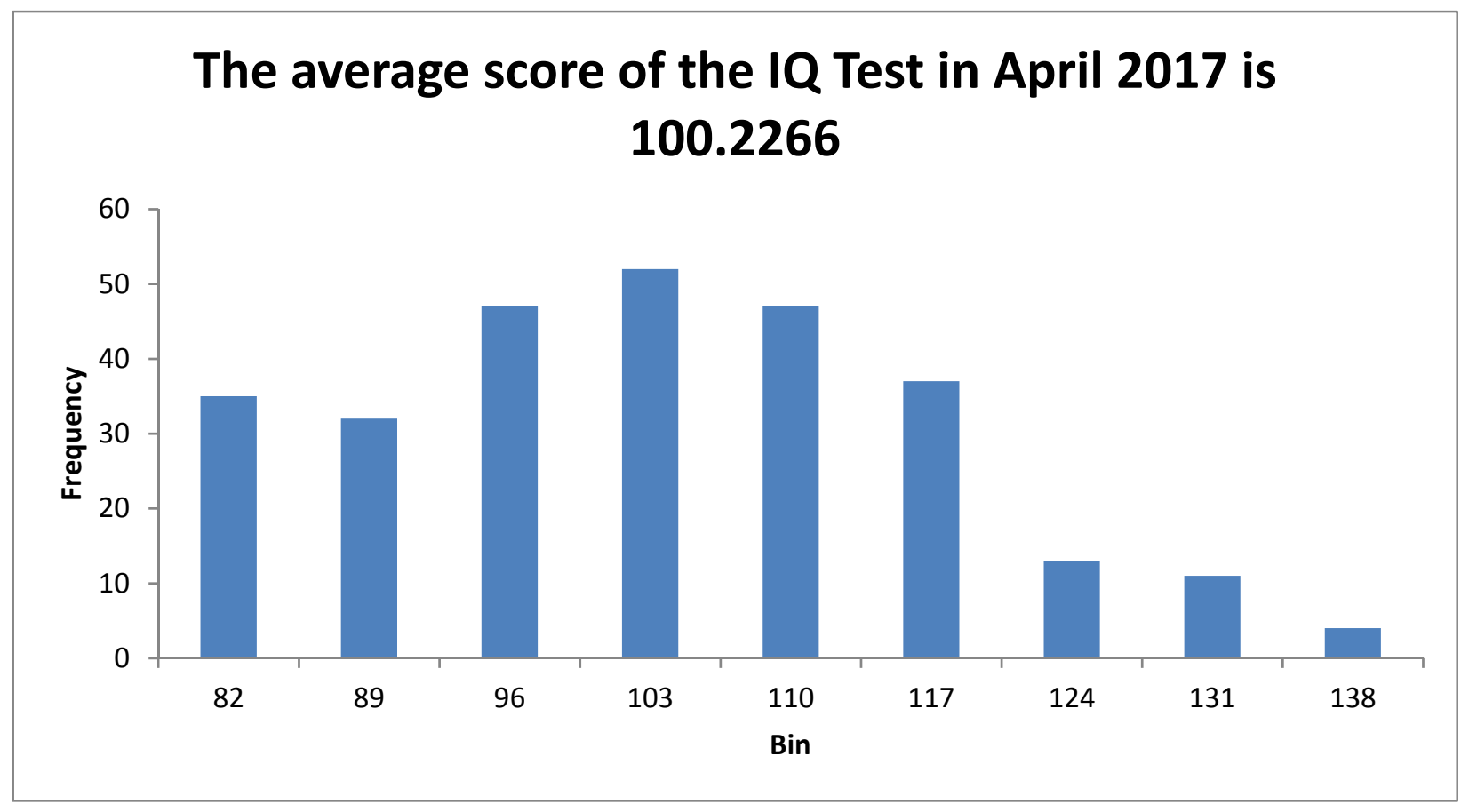

Figure 4. The Histogram of the IQ Test at NVT in April 2017

\section{Conclusion}

In this study, an IQ test has been used to test the "intelligence" of two pupil groups: one is studying the bilingual program and the other is learning the monolingual program plus English subject as a foreign language. The study discovered that both groups have increased the IQ score after seven months at schools. This evidence proves that IQ scores are not fixed but can increase through ages of children from 6 to 11 as well as through education. However, the group of bilingual learners has higher increase of IQ scores in comparison with the monolingual group, proving the bilingual education can help to better improve the intelligence of children. This is agreeable with the results of many previous researches. 
Therefore, it is highly recommended that all young children should be learnt at least one more language beside their native language. And where it is applicable, young children should study bilingual education programs and be placed in bilingual environment. This will help the children, as stated clearly above, not only to know another language and culture, but also to increase their "intelligence" by increasing their IQ scores.

\section{References}

Baker, C. (2006). Foundations of bilingual education and bilingualism (4 ${ }^{\text {th }}$ Edn.). Multilingual Matters Ltd. Clevedon, U.K.

Bialystok, E. (2001). Bilingualism in development: language, literacy, \& cognition. Cambridge University Press, Cambridge, U.K. https://doi.org/10.1017/CBO9780511605963

Bialystok, E. (2011). Reshaping the mind: the benifits of bilingualism. Canadian Journal of Experimental Psychology, 65(4), 229-235. https://doi.org/10.1037/a0025406

Cambridge International Examinations (CIE, 2016). Retrieved from http://www.cie.org.uk

Cassidy, S., Roche, B., \& Hayes, S.C. (2011). A relational frame training intervention to raise intelligence quotients: a pilot study. The Psychological Record, 61, 173-198. https://doi.org/10.1007/BF03395755

Cumming, B. (2012). Implementing a successful bilingual education program in Japan: support for minority languages and the present climate of bilingual education. The Journal of the Faculty of Foreign Studies, 44, $77-101$.

Cummins, J. (2003). Bilingual education: basic principles. In J. Dewaele, A. Housen, \& L. Wei (Eds.), Bilingualism: Beyond Basic Principles (pp. 56-66). Multilingual Matters Ltd., Buffalo, U.S.A. https://doi.org/10.4324/9780203416709_chapter_1

Forgeard M., Winner E., Norton A., \& Schlaug G. (2008). Practicing a musical instrument in childhood is associated with enhanced verbal ability and nonverbal reasoning. PLOS ONE. https://doi.org/10.1371/journal.pone.0003566

Genesee, F. (1987). Learning Through Two Languages. Newbury House Publishers. Cambridge, Mass. U.S.A

Hamers, J. F., \& Blanc. M. H. A. (2000). Bilinguality \& Bilingualism (2nd ed.). Cambridge University Press, Cambridge, U.K. https://doi.org/10.1017/CBO9780511605796

Hille, K., Gust, K., Bitz, U., \& Kammer, T. (2011). Associations between music education, intelligence, and spelling ability in elementary school. Advances in Cognitive Psychology, 7, 1-6. https://doi.org/10.2478/v10053-008-0082-4

Martensson, J., Eriksson, J., Bodammer, N.C., Lindgren, M., Johansson, M., Nyberg, L., \& Lovden, M. (2012). Growth of language-related brain areas after foreign language learning. Neuroimage, 63(1), 240-244. https://doi.org/10.1016/j.neuroimage.2012.06.043

Mechelli, A., Crinion, J.T., Noppeney, U., O’Doherty., Ashburner, J., Frackowiak, R.S., \& Price, C.J. (2004). Neurolinguistics: Structural plasticity in the bilingual brain. Nature, 431, 750-757. https://doi.org/10.1038/431757a

Olulade, O. A., Jamal, N. I., Koo, D. S., Perfetti, C. A., LaSasso, C., \& Eden, G. F. (2016). Neuroanatomical evidence in support of the bilingual advantage theory. Cereb Cortex, 26(7), 3196-3204. https://doi.org/10.1093/cercor/bhv152

Roche, B., Cassidy, S., \& Stewart, I. (2013). Nurturing genius: Realizing a foundational aim of psychology. In Kashdan, T., \& Ciarrochi, J. (Eds), Cultivating well-being: Treatment innovations in positive psychology, acceptance and commitment therapy, and beyond. Oakland, CA, New Harbinger.

Schellenberg, E. G., \& Peretz, I. (2008). Music, language and cognition: Unresolved issues. Trends in Cognitive Sciences, 12, 45-46. https://doi.org/10.1016/j.tics.2007.11.005

Schlaug, G. (2015). Musicians and music making as a model for the study of brain plasticity. Progress in Brain Research, 217, 37-55. https://doi.org/10.1016/bs.pbr.2014.11.020

Skutnabb-Kangas, T. (2000). Linguistic human rights in education? In Linguistic genocide in education - or worldwide diversity and human rights? (pp. 567-649). Lawrence Erlbaum Associates. Mahwah, New Jersey, U.S.A. 